\title{
La Historia de Roma en la obra dramática de Ramón de la Cruz y Vicente Rodríguez de Arellano ${ }^{1}$
}

\author{
Cristina MARTín Puente \\ Universidad Complutense de Madrid \\ cmartin@filol.ucm.es
}

Recibido: 4 de noviembre de 2012

Aceptado: 20 de noviembre de 2012

\section{RESUMEN}

Metastasio y Apostolo Zeno constituyen un puente entre los autores clásicos y los dramaturgos españoles del siglo XVIII, como Ramón de la Cruz y Vicente Rodríguez de Arellano, que no sólo escriben obras originales, sino que también realizan versiones de los melodramas italianos. Tanto los autores italianos como los españoles ponen en escena su particular visión de la Historia de Roma para el gran público con extraordinario éxito.

Palabras clave: Teatro del siglo XVIII. Apostolo Zeno. Metastasio. Ramón de la Cruz. Vicente Rodríguez de Arellano. Autores grecolatinos. Historia de Roma.

Martín Puente, C., «La Historia de Roma en la obra dramática de Ramón de la Cruz y Vicente Rodríguez de Arellano», Cuad. Fil. Clás. Estud. Lat. 32.2 (2012) 347-360.

\section{The History of Rome in the play of Ramón de la Cruz and Vicente Rodríguez de Arellano}

\begin{abstract}
Metastasio and Apostolo Zeno provide a bridge between the classics and the eighteenth-century Spanish playwriters, as Ramón de la Cruz and Vicente Rodríguez de Arellano, who not only write original work, but also made versions of Italian melodrams. Both Italian and Spanish authors staged their particular vision of the history of Rome to the public whith extraordinary success.

Keywords: Eighteenth century theater. Apostolo Zeno. Metastasio. Ramón de la Cruz. Vicente Rodríguez de Arellano. Greek and Latin authors. History of Rome.

Martín Puente, C., «The History of Rome in the play of Ramón de la Cruz and Vicente Rodríguez de Arellano», Cuad. Fil. Clás. Estud. Lat. 32.2 (2012) 347-360.
\end{abstract}

Sumario 1. Introducción. 2. Ramón de la Cruz y Cano (1731-1794). 3. Vicente Rodríguez de Arellano y del Arco (1750-1815). 4. Conclusiones. 5. Referencias bibliográficas.

\footnotetext{
${ }^{1}$ Este trabajo se inscribe en el grupo de investigación UCM 930136 «Historiografía de la literatura grecolatina en España», convocatoria GR35/10-A: «Fuentes documentales para HLGE0». 


\section{INTRODUCCIÓN}

En el convulso periodo de la transición de la Ilustración al Liberalismo un grupo de dramaturgos españoles, considerados «populares» porque cosechan gran éxito en diversos géneros y temática, adaptan un número importante de melodramas italia$\operatorname{nos}^{2}$ y componen algunas piezas originales sobre ciertos episodios de la Historia de Roma protagonizados por personajes que han gozado de mayor o menor fama a lo largo de los siglos. La demanda de estrenos es muy alta y ellos saben que estos argumentos tienen muchas posibilidades dramáticas y un éxito asegurado. De hecho tenemos noticia de que, tras asistir a la representación de estos melodramas con fastuosas escenografías que los hacían muy atractivos para el gran público, los empresarios y los actores, los autores se animaron a acometer ellos mismos alguna adaptación (Garelli 1997, p.131), quizá por el prurito de ofrecer una versión de Metastasio mejor que las que se venían representando en la primera mitad del siglo XVIII. Uno de estos autores es Ramón de la Cruz y Cano (1731-1794) y el resto fueron englobados despectivamente por Lista dentro de la denominada «escuela de Comella», a pesar de que son personalidades muy dispares: Antonio Valladares de Sotomayor (1737/8-1820), Vicente Rodríguez de Arellano (1750-1806), Gaspar Zavala y Zamora (1750-1813 ¿1824?) y Luciano Francisco Comella (1751-1812). Los cinco demuestran que el subgénero dramático de argumento romano ${ }^{3}$, que ya habían cultivado Lope de Vega, Cervantes, Calderón de la Barca, Shakespeare, Racine, Corneille, etc., sigue suscitando el interés de quienes escriben dramas originales o adaptan obras de otras literaturas al español y, lo más importante, el interés del público. No es casual que, por ejemplo, Fr. Pedro de la Vega publicase una traducción de las Décadas de Tito Livio en 1793, que entre 1866 y 1869 la editorial Salvador Manero publicase una colección de piezas teatrales en ocho volúmenes titulada Teatro selecto, antiguo y moderno, nacional y extranjero, que recopila originales y versiones de las obras europeas más importantes e incluye algunas obras romanas de Metastasio (Marco García 1998), o que el gibraltareño William Macpherson editase entre 1873 y 1897 sus traducciones de los dramas de Shakespeare con importantes prólogos introductorios, entre los que están Julio César, Coriolano, Antonio y Cleopatra, Timón de Atenas y Troilo y Crésida.

Es opinión hoy muy extendida que las traducciones y adaptaciones influyeron mucho en la renovación del teatro español, a pesar de las reservas formuladas por los clasicistas $^{4}$. Esta evolución también es patente en el caso del subgénero de los dramas romanos $^{5}$, que siguió mostrando pleno vigor en el siglo XIX, si bien los personajes que

\footnotetext{
${ }^{2}$ Si bien autores como Saviñón adaptan también obras francesas.

${ }^{3}$ Para los estudiosos del teatro las obras romanas serían comedias historiales heroicas, pues sus protagonistas son ejemplo de heroísmo y patriotismo abnegado, y estarían dentro del teatro espectacular, que es uno de los tipos del teatro popular, cuya principal característica es que fue escrito para representarse (Angulo Egea 2004, pp.12-13).

${ }^{4}$ Moratín hijo cree que en este teatro perdura el gusto tardo-barroco, obstáculo a la reforma del teatro español según los cánones clasicistas (Marco García 1998, p.41, Fernández Cabezón 1989, Garelli 1995 y 1997).

${ }^{5}$ Aunque gran parte de estas obras y autores se pueden encontrar en los múltiples catálogos publicados sobre la literatura dramática original y traducida del siglo XVIII en España y afortunadamente cada vez más
} 
interesaron a los autores fueron otros, Catilina, los hermanos Graco, el Bruto que derrocó la monarquía, el Bruto que quitó la vida a César, los emperadores Nerón, Tiberio y Calígula, Lucrecia, Virginia, etc. (Martín Puente 2003, 2005a, 2005b, 2005c, 2009a, 2009b, 2010). En las obras protagonizadas por romanos se teje una compleja red de relaciones literarias múltiples directas e indirectas, que va desde los autores grecolatinos de época clásica hasta los españoles de finales del siglo XVIII, incluyendo a autores de diversas épocas y lugares, entre los que destacan Petrarca, Shakespeare, Calderón de la Barca, Corneille, Racine, Apostolo Zeno, Metastasio, Luzán, Ignacio López de Ayala, etc., todos los cuales poseían una vasta cultura y conocían a los clásicos. En este sentido, como dice Claudio Guillén (1985, p.345), las traducciones han actuado como una forma de comunicación ternaria que abraza segmentos diferentes en el tiempo y en el espacio.

En todo este panorama hay que destacar un hito, la llegada de Farinelli a la corte española, uno de los cantantes más famosos del siglo XVIII, llamado por el propio Felipe V para aliviar su melancolía ${ }^{6}$ en 1737 , pues éste hizo venir a Metastasio (16981782) a España y montó fundamentalmente sus melodramas, que gozaron de gran éxito durante todo el reinado de Fernando VI, traducidos, abreviados y adaptados al gusto del gran público español por el propio Farinelli, por el crítico y erudito Luzán (Fernández Fernández 2001), por hombres de teatro como Antonio Bazo, Ramón de la Cruz, Vicente Rodríguez de Arellano, Gaspar Zavala y Zamora, José Ibarro, Ignacio García Malo, Juan Marugán, Cándido María Trigueros, Manuel Lassala, Joseph Ibáñez Gassía, etc. e incluso por otros no relacionados con la escena, como los jesuitas Burriel y Céspedes ${ }^{7}$. Aunque estas obras fueron criticadas por los clasicistas, alcanzaron gran éxito, porque introdujeron el nuevo espectáculo del melodrama europeo sin romper drásticamente con la tradición cómica tardobarroca - de hecho tienen influencia de Calderón-, al contrario de lo que intentó la reforma moratiniana, y porque Metastasio hizo una lectura alegórico-moral y política de la romanidad, como suma del heroísmo, el respeto a las leyes y el patriotismo que está por encima de la vida del individuo, virtudes que casan bien con las cristianas ${ }^{8}$. De todos modos las adaptaciones

obras se pueden consultar en Internet (por ejemplo, en la Biblioteca Virtual del Patrimonio Bibliográfico o la Biblioteca Virtual Miguel de Cervantes), como en ellos no se suele tener en cuenta la temática y los títulos a veces no son explícitos, estas obras pasan bastante desapercibidas y no han sido objeto de estudio, salvo alguna excepción.

${ }^{6}$ El rey nombró al gran cantante de ópera músico de cámara, criado familiar y primer ministro, y éste adquirió un gran éxito en Madrid, Barcelona, Cádiz, Sevilla, Valencia, etc.

${ }^{7}$ Según Garelli (1997, p.128), el hecho de que haya tantas traducciones de un mismo libreto y casi siempre los adaptadores sean desconocidos (aunque sí aparece el nombre del compositor de la música, del director de escena o de la compañía para la que se hace la versión) se debería a que los traductores trabajaban por encargo sin autonomía, los resultados eran de escasa calidad y primaba la música sobre el texto. Para otros autores y traducciones anónimas al español, véanse Stoudemire 1941, p.185 y Carreras - Leza 2000. Para el caso de las traducciones al portugués, en concreto las de Francisco Luiz Ameno, publicadas en 1755, véase Abalada 2011.

${ }^{8}$ Quizá la importancia de la moralidad en la obra de Metastasio es la razón de que los jesuitas españoles expulsados y asentados en Italia, de la talla de Esteban de Arteaga o Juan Andrés, no sólo lo tradujesen sino que también le dedicasen su atención en trabajos de crítica literaria, juzgándolo desde todos los puntos de vista con diferente valoración, pero reconociendo siempre su éxito (Molina Castillo 1999, Rossi 1967 y Sala Valldaura 1994). 
experimentaron una notable evolución que, por ejemplo, hizo desaparecer a los graciosos de las versiones más antiguas, y contribuyeron a renovar el teatro español del siglo XVIII. Pero en 1799 Carlos IV decretó la prohibición de las representaciones en lenguas distintas del español y cerró los Reales Sitios, Farinelli marchó a Bolonia y la ópera entró en declive, hasta que en la década de los noventa retornó a su anterior esplendor porque se adaptó a la nueva sensibilidad prerromántica (Arce 1968, apud Fernández Cabezón 1989, p.81).

En la vasta producción de Metastasio ${ }^{9}$ es palmario su interés por la Historia de Roma en las siguientes obras dramáticas ${ }^{10}$ : Giustino (representada en 1712 y publicada en $1717)^{11}$, Catone in Utica (1727, hay posteriores reediciones) ${ }^{12}$, Didone abbandonata $(1724)^{13}$, Ezio (1728), Adriano in Siria (1732) ${ }^{14}$, Clemenza di Tito (1734), Il sogno di Scipione (1735), Attilio Regolo (1750), Atenaide, ovvero Gli affetti generosi (1762) y Romolo ed Ersilia (1765). El interés por Roma le llega por varias vías, como ha puesto de manifiesto Tatti (2001). Una es la reconsideración epistemológica de la recepción de lo antiguo y la nueva filosofía de la historia que en Nápoles llevan a cabo Caloprese, Gravina, Giannone y Vico (quien en el «Corollario d'intorno all'eroismo de 'primi popoli», capítulo de su Scienza nuova, pasa revista a los héroes romanos Bruto, Escévola, Manlio, Curcio, Decio, Fabricio, Curio, Atilio Régulo). Estos intelectuales consideran la historia romana como fundamento ético y espiritual imprescindible para la civilización occidental. Otra vía es el teatro de Gravina ${ }^{15}$ (autor de las tragedias Appio Claudio, Papiniano, Servio Tullio), Pansuti (Orazia, Bruto, Sofonisba, Virginia, Sejano), Martello (La morte di Nerone) y Conti (Il Cesare, Lucio Giunio Bruto, Marco Bruto), seguidores todos del modelo francés. La última es el teatro musical de Stampiglia (Trionfo di Camilla), Gerolamo Frigimelica Roberti (Trionfo della libertà), Matteo Noris (Attilio Regolo, Catone Uticense), Nicholas Francis Haym (Cesare in Egitto), Dario Varotaria (Il Cesare amante), Anonio Salvi (Berenice regina di Egitto overo le gare di amore e di politica) y, sobre todo, Apostolo Zeno. Zeno es un componente muy destacado de la Academia letteraria d'Arcadia y uno de los impulsores de la reforma de la ópera seria en la parte literaria, en virtud de la cual los libretos debían seguir los

\footnotetext{
${ }^{9}$ A lo largo de su vida este autor, escribió numerosos melodramas, oratorios, cantatas, cancioncillas, etc.

${ }^{10}$ Para la opinión de Arteaga sobre alguna de estas obras, véase Rossi 1967, pp.255-257. Otras obras enmarcadas en la Antigüedad, pero en las que no aparecen romanos, son Ciro reconocido, Demetrio, Demofonte, Artaxerxes, Temístocles, Antígono, Alejandro en las Indias, Siface y Zenobia. Aunque Stoudemire (1941, p.191) atribuye a Metastasio también la ópera Giulio Sabino (1781), ubicada en la Galia, cuando, en tiempos del Emperador Vespasiano (70 d.C.), al parecer, se trata de un libreto de Pietro Giovannini con música de Giuseppe Sarti. Sobre la importante presencia de la Historia de Roma en la ópera, véase Lapeña Marchena (2004).

${ }^{11}$ Metastasio compuso esta tragedia al estilo de las de Séneca siendo muy joven y su tutor Gravina la imprimió, pero Metastasio renegó de ella.

12 Tatti (2001, p.289) sostiene que se atiene al texto de Plutarco, que es la primera fuente sobre el suicidio.

13 Cf. Martín de Doria (2002).

${ }^{14}$ Cf. Vidal - Cabrera (2005, pp.314-8).

15 Vincenzo Gravina, tutor de Metastasio, fundó la Academia letteraria d'Arcadia en Roma en 1688, como reacción al amaneramiento exagerado de los manieristas y la estética excesiva y afectada del barroco. Los artistas de este grupo buscaban la simplicidad asociada a los habitantes de la primitiva Arcadia, considerada como el país de la felicidad, y se inspiraron en las fuentes clásicas, especialmente en los poetas griegos que cultivaron el género.
} 
principios de la tragedia griega clásica, tal como se recogía en la Poética de Aristóteles y se aplicaba en la obra de Racine y otros autores franceses, cumpliendo las unidades de acción, tiempo y lugar. Los personajes no debían ser más de ocho y quedaban excluidos los cómicos, los argumentos debían simplificarse y la acción quedaba dividida rígidamente en recitativos y arias. Por otro lado, Zeno publicó dos volúmenes de Dissertazioni vossiane, suplementos a las investigaciones de Vossius sobre los historiadores latinos, en los cuales debió de encontrar inspiración para los libretos de óperas sobre Historia Antigua, que gozaron de gran éxito: Eumene (1697), Lucio Vero (1700), Griselda (1701), Pirro (1704) -traducida libremente al español por Rodríguez de Arellano con el título de Pirro y Casandro (1798)-, L'amor generoso (1707), Merope (1711), Lucio Papirio dittatore (1719) y Caio Fabbrizio (1729). Zeno, el primer libretista italiano que no se constriñe a los temas mitológicos e introduce temas históricos en la ópera, pensaba que los héroes de la antigüedad grecorromana inspiraban virtudes como la magnanimidad del perdón, la moderación, la amistad constante, el amor conyugal, etc., cualidades todas que podían ser atribuidas al soberano (Tatti 2001, pp.279-282). Fue precisamente este autor, cuya influencia en la literatura española ha sido poco estudiada, quien abrió las puertas de Viena a Metastasio, que, convertido en poeta imperial en 1730, destaca por la musicalidad de sus versos, un lenguaje muy cuidado y la atenuación de las pasiones, huyendo de los excesos precedentes. Además elige episodios de la historia de Roma basados en autores latinos y griegos de muy diferentes épocas y relevancia, en humanistas y en autores italianos, franceses, ingleses y españoles anteriores a él, para componer melodramas con una trama y un final similares en los que el amor es el tema principal ${ }^{16}$. En ellos retrata a los reyes Curcio y Porsena, a Julio César y a los emperadores Tito, Adriano, Valentiniano III y Justino II como hombres magnánimos, muy cercanos a los soberanos del Despotismo Ilustrado y a los protagonistas masculinos (Atilio Régulo, Escipión, Catón, Aecio) y femeninos (Dido, Hersilia, Clelia, Servilia, etc.) como modelos de virtudes cívicas cual la lealtad, la valentía o la humildad.

\section{RAMÓN DE LA CRUZ Y CANO (1731-1794)}

Ramón de la Cruz fue fundamentalmente un hombre de teatro y destacó por haber compuesto más de trescientos sainetes populares de gran éxito (Cotarelo y Mori 1899). Aunque había sido duramente criticado por neoclasicistas como Moratín padre, Nifo, Tomás de Iriarte, Samaniego o Signorelli, tras caer en 1773 el gobierno del Conde de Aranda, protector de la estética neoclásica, alcanzó su apogeo en la vida teatral de la Corte, llegando a controlar el Teatro de la Cruz y el Teatro del Príncipe, gracias a que gozaba de los favores del Ayuntamiento de Madrid y de la protección del Duque de Alba, a quien acompañaba en sus viajes. También adaptó obras dramáticas, como Andrómeda y Perseo de Calderón e Ifigenia de José de Cañizares, y tradujo a Apostolo Zeno, Metastasio, Racine, Voltaire, Shakespeare, etc., reduciendo es-

${ }^{16}$ Ya el jesuita Arteaga le reprochó que abusaba de este tema (Rossi, 1967, p.263). 
cenas, añadiendo o eliminando personajes, complicando la trama, españolizando los referentes, etc. a su voluntad, en algunos casos sin firmar sus traducciones o adaptaciones (Bittoun-Debruyne 1995). Además Ramón de la Cruz popularizó el teatro musical de Alfieri, aunque su éxito vino después favorecido por su utilización política (Sala Valldaura 1994, p.157), pero no tradujo ninguna de sus obras romanas, como sí hizo Saviñón. Entre sus obras, muchas de las cuales publicó en una colección incompleta de diez tomos (1786-1791), hay cinco relacionadas con Roma ${ }^{17}$ : cuatro traducciones de obras italianas de la primera mitad del siglo XVIII y una Introducción para la tragedia Numancia destruida de López de Ayala.

Del afamadísimo Metastasio tradujo Ezio (1728) con el título de Ecio triunfante en Roma $(1767)^{18}$, obra que también el jesuita Benito Antonio de Céspedes tradujo, no sabemos si antes o después, con el título de Ecio y está basada en la Crónica de Próspero de Aquitania, los Historiarum De Occidentali Imperio Libri XX de Carolus Sigonius (humanista italiano del siglo XVI), etc., según Metastasio. Los personajes son el emperador Valentiniano III, Fulvia, hija de Máximo, Ecio, general y enamorado de Fulvia, Honoria, hermana de Valentiniano y enamorada en secreto de Ecio, Máximo, patricio romano, confidente y enemigo secreto de Valentiniano, y Varo, capitán de pretorianos y amigo de Ecio. Cuando Ecio vuelve a Roma después de vencer a Atila en la Batalla de los Campos Cataláunicos, se entera de que el emperador se quiere casar con su prometida, Fulvia. El padre de ésta, Máximo, pretendía que, tras la boda, la joven matase al emperador, pero ella se opone. Máximo intenta matar a Valentiniano, pero deja caer las sospechas sobre Ecio. Ella declara todo y Valentiniano, aunque perdona a Ecio y le concede la mano de Fulvia, manda que lo maten en secreto. Finalmente Ecio salva a Valentiniano de morir a manos de los soldados y se casa con Fulvia, Atila se casa con Honoria y Máximo se da muerte. Así pues, el protagonista se salva, aunque los historiadores de la Antigüedad nos cuentan que Aecio, conocido como 'el último romano', murió asesinado por el emperador Valentiniano III (454 d. C.). La traducción de Ramón de la Cruz, según Garelli (1997, pp.131 y 136), reflejaría un apoyo incondicional a la monarquía absoluta, pero sustituye la clemencia típica de los monarcas de Metastasio (en este caso de Valentiniano, que salva la vida al conspirador Massimo) por el suicidio del regicida, todo ello en una atmósfera de solemnidad donde la música tiene un importante papel.

También hizo una versión de Attilio Regolo (1750) con el título Entre la patria y la vida, no hay más vida que la patria. Atilio Régulo (1778). Obra que Céspedes tradujo con el título Atilio Régulo en fecha indeterminada. Attilio Regolo (1750) aborda un episodio protagonizado por el cónsul Marco Atilio Régulo, que conocemos por Eutropio, Floro, Juan Zonaras, el Epítome de Livio, Polibio, Orosio, Aurelio Víctor, Diodoro Sículo, Apiano, Dion Casio, Valerio Máximo, Cicerón, Horacio y Silio Itálico, aun-

\footnotetext{
${ }^{17}$ Aparte de estas obras tiene, al menos, otra que se localiza en la Antigüedad. Se trata de una versión libre de la Zenobia (1740) de Metastasio que lleva por título de Más puede el hombre que amor. Querer a dos y ser firme (1768).

${ }^{18}$ El personaje Flavius Aetius es conocido en italiano como Ezio y en las traducciones al español de la obra de Metastasio se le da el nombre de Ecio, pero hoy en español es conocido como Aecio.
} 
que Metastasio sólo cita en el argumento explícitamente a Apiano, Juan Zonaras, Cicerón, Horacio, añadiendo «y otros». Los personajes son Régulo, Manlio, cónsul, Atilia y Publio, hijos de Atilio Régulo, Barce, noble africana esclava de Publio, Licinio, tribuno de la plebe y enamorado de Atilia y Amílcar, embajador de Cartago y enamorado de Barce. Atilio Régulo, apresado por los cartagineses durante la primera guerra púnica, es enviado a Roma para negociar la paz con la promesa de que regresaría. Tras convencer al Senado de que no aceptase las condiciones del enemigo, volvió a Cartago, donde murió torturado, convirtiéndose en paradigma de virtud cívica y de fidelidad al juramento prestado, incluso al enemigo. La obra acaba con Régulo despidiéndose de todos y partiendo a su fatal destino. Esta obra es para Garelli (1997, p.136) un ejemplo de que los adaptadores quieren acercar al público un nuevo teatro que no es simple evasión, sino que tiene también una función moralizante y didáctica, en este caso el protagonista quiere servir de ejemplo a los romanos al enfrentarse al enemigo, aun estando seguro de encontrar así la muerte.

Seguramente de la Cruz quedó tan satisfecho con los resultados obtenidos con estas obras que buscó otros autores que cultivasen esta temática y apostó por el primer libretista italiano que también abordó temas históricos en la ópera, Apostolo Zeno, el cual había gozado de gran éxito hasta la irrupción de Metastasio. De él adaptó Lucio Papirio dittatore (1719) con el título El severo dictador y vencedor delincuente, Lucio Papirio y Quinto Fabio (edición de 1775, representada en 1791 durante quince días y seis veces más hasta 1803). Los personajes son Lucio Papirio, dictador, Emilia, hija del dictador, Q. Fabio, Marco Fabio, padre de Q. Fabio, Sabina, otra hija del dictador, Apio, tribuno de la plebe, y el Sumo sacerdote. Lucio Papirio fue nombrado dictador en la guerra contra los samnitas y nombró maestro de caballería a Quinto Fabio Rutiliano. Cuando el dictador tuvo que volver a Roma a tomar nuevos auspicios, dejó el ejército a cargo de Fabio con la orden de no combatir contra los samnitas, pero éste desobedeció y Papirio lo condenó a morir. Entonces Fabio se refugió entre las legiones sublevadas y huyó a Roma, donde su padre convocó al Senado y al pueblo que intercedieron para que lo absolviera a través del tribuno de la plebe. Esta historia nos es transmitida por Tito Livio y otros autores, pero le debe a Apostolo Zeno los amores de la hija del dictador, Emilia, con Q. Fabio. También tradujo Caio Fabbrizio (1729) con el título de Cayo Fabricio cónsul (obra estrenada y publicada en 1783 con música de Pablo Esteve, pero hoy perdida, según indica Cotarelo y Mori 1899, p.167).

Es destacable que Ramón de la Cruz elija traducir tres obras sobre episodios de la República protagonizados respectivamente por Cayo Fabricio, Lucio Papirio y Atilio Régulo, así como otro del final del Imperio protagonizado por Aecio. Los cuatro varones romanos que dan título a las obras se caracterizan por ser ciudadanos ejemplares a los que no les importan las consecuencias derivadas de mantenerse fieles a su palabra a toda costa. También vemos que a Ramón de la Cruz impone nuevos títulos a sus versiones que son más extensos que los originales y hablan un poco más del protagonista o dan algún detalle del argumento -a diferencia, por ejemplo, del jesuita Benito Antonio de Céspedes, que respeta los títulos originales de Metastasio-.

Además de estas obras compuso una Introducción para la tragedia Numancia destruida de Ignacio López de Ayala (1778). En ella el personaje de Simón convence a 
otros tres personajes de que vayan a ver la tragedia porque el autor y el tema son españoles y por «ser un caso nuevo y ejemplar» y el autor defiende la tragedia neoclásica española de tema nacional. Lo que pone de manifiesto que, a pesar de que Ramón de la Cruz era despreciado por los que cultivaban el llamado teatro erudito, él mismo conocía, apreciaba y admiraba este teatro.

\section{VICENTE RODRÍGUEZ DE ARELLANO Y DEL ARCO (1750-1815)}

El navarro Vicente Rodríguez de Arellano y del Arco (1750-1815), conocido también por los pseudónimos de Alberto de los Ríos, Gil Lorenzo de Arozar y Silvio del Arga y educado con los jesuitas, tenía una buena formación, hasta el punto de que optó, aunque sin éxito, a la cátedra de Filosofía en el Real Seminario de Nobles y ejerció como escribiente de la Real Biblioteca hasta 1809. En el plano político participó en la Guerra de la Independencia y formó parte de La Camarilla, gobierno en la sombra de Fernando VII, de modo que se sitúa en el polo opuesto a liberales como Antonio Valladares de Sotomayor, que fue perseguido por la Inquisición, o Antonio Saviñón, contra el que el rey ejerció una enorme represión y murió en la cárcel. En el plano literario adaptó comedias del teatro clásico, escribió tragedias, melodramas, comedias sentimentales, óperas, etc., teniendo un especial éxito como libretista de tonadilla (junto con Moncín, Zavala y Zamora, etc.), como compositor de melólogos (junto con Comella) y como poeta (en sus Poesías varias [1806] encontramos anacreónticas, epigramas, fábulas, romances, etc.). A pesar de todo ello, Alberto Lista lo incluyó en la que llamó «escuela de Comella» y la crítica neoclásica lo trató mal (Aguilar Piñal 1981, pp.193-210, Fernández González 2003, pp.722-735). De sus dramas cinco, al menos, están relacionados con la historia de Roma ${ }^{19}$.

La noche de Troya $(1797)^{20}$ es una obra en un acto y en verso aparentemente original que pone en escena la salida de Eneas con su padre y su hijo de Troya, tema que narra Virgilio en el libro II de la Eneida de Virgilio y otras obras españolas del Siglo de Oro y posteriores ${ }^{21}$. La obra comienza con Eneas junto a los sepulcros de Héctor y Paris acompañado de Arsenes, después de que los griegos hayan entrado en la ciudad. Eneas en su casa oye a la sombra de Héctor y quiere salir a luchar, pero An-

\footnotetext{
${ }^{19}$ Otras obras ambientadas en la Antigüedad son El Aníbal (1792), que, a pesar de lo que cabría esperar, no tiene ni un solo personaje romano, Pirro y Casandro (1798), traducción de Pirro (1704) de Apostolo Zeno, La venganza de Nino o Semíramis (1800), Palmis y Oronte (1798), Himeneo (1799) y El gran Seleuco (1799).

${ }^{20}$ Además de esta edición, donde se dice que el famosísimo actor Isidoro Maiquez interpreta a Eneas, hay al menos una de 1813 y otra de 1819 , que demuestran su éxito.

${ }^{21}$ Por ejemplo, Fernando de Herrera (1534-1597) tiene un soneto titulado «Incendio de Troya», Lope de Vega (1562-1635) tiene un poema dedicado a Helena titulado «Árdese Troya y sube el humo oscuro», Jerónimo de Cáncer y Velasco (finales del siglo XVI - 1655) tiene un romance titulado «Al incendio de Troya». También sabemos de varias obras de teatro, como el entremés La destrucción de Troya (1647), falsamente atribuido a Góngora, La destrucción de Troya (siglo XVII) de Cristóbal de Monroy, Troya abrasada (ca. 1640) de Calderón de la Barca y Juan de Zabaleta, el auto sacramental El robo de Elena y destrucción de Troya (siglo XVII) de Rojas Zorrilla y la tragicomedia anónima Troya abrasada (1791).
} 
quises le insta a que salve su vida y la de su familia. Cuando salen entre las llamas Eneas, su padre, su hijo y su esposa, Eubeo es atacado por los griegos y le arrebatan a Creusa. Eneas se lamenta profundamente, entonces aparece Venus, le explica que su esposa ha muerto y le vaticina que en Hesperia acabarán sus trabajos, se casará y fundará un nuevo reino. Él acepta estos designios. Muy relacionada con esta obra está la siguiente, también basada en un conocidísimo pasaje de la Eneida.

Dido abandonada (escrita en 1791, publicada en 1795 y reeditada en 1819) es una traducción libre en octosílabos y en tres actos de la Didone abbandonata (1724) de Metastasio (Garelli 1995) sobre la historia de amor truncada de Dido y Eneas que recoge el libro IV de la Eneida. La obra comienza con Anquises diciendo en sueños a Eneas que tiene que partir. Esto le causa gran dolor, porque ama a Dido profundamente, pero debe obedecer los designios divinos. Yarba, el rey de Mauritania aparece haciéndose pasar por su embajador, para obtener la mano de Dido y trata de matar a Eneas. Osmida, consejero de Dido, pretende traicionarla y ayudar a Yarba. Araspe, consejero de Yarba y enamorado de Selene, la hermana de Dido, salva a Eneas de la muerte y trata todo el tiempo de que el rey conserve su honor y sea clemente. Dido quiere que Yarba muera, pero Eneas le dice que eso destruirá Cartago, como ocurrió con Troya y cuenta el fin de su ciudad, siguiendo con bastante fidelidad el libro II de la Eneida (quizá al traducir este pasaje Arellano pensó en escribir una obra sobre la salida de Eneas de Troya). Dido quiere vengarse del troyano haciéndole creer que se casará con Yarba y en un intento desesperado quiere que Eneas la deje ir con él. Finalmente, como Dido no accede a casarse, la ciudad y la reina son pasto de las llamas. Esta traducción es posterior a dos que se representan en 1752, una en Barcelona y otra en Madrid, a la de Benito Antonio de Céspedes (anterior a 1787), a El valiente Eneas, por otro título Dido abandonada (1757) de Joseph de Ibáñez Gassía y a Dido abandonada de Manuel Lassala (Bolonia 1783). En España, donde Dido protagonizaba muchos dramas del Siglo de Oro y posteriores, las traducciones de la obra de Metastasio contribuyeron aún más a que la leyenda siguiera viva ${ }^{22}$.

Cayo Fabricio (1799, hay un manuscrito de 1804) muy posiblemente es una traducción de la obra Caio Fabbrizio (1729) de Apostolo Zeno ${ }^{23}$, posterior a la que había publicado en 1783 Ramón de la Cruz. El cónsul romano Cayo Fabricio está en la corte de Pirro, rey de Epiro y Macedonia, con el mensaje de que Roma no se rinde, pero tiene poco protagonismo en esta intriga amorosa con final feliz. Pirro, que tiene como consejero y confidente a Cineas, está locamente enamorado de su prisionera Sestia, hija de Fabricio y prometida de Volumnio, y quiere que sea su esposa, olvidándose de su compromiso con la enojadísima Bircena, princesa de Iliria, a quien acompaña y sirve de confidente Turio, gobernador de Tarento. Sestia cree ver a Volumnio (al

\footnotetext{
${ }^{22}$ Algunas de ellas son la Tragedia de Dido y Eneas de Juan del Cirne (1536?), Dido y Eneas de Guillén de Castro (1613), El más piadoso troyano, Dido y Eneas de Francisco de Villegas (1669), Los amores de Dido y Eneas de Cristóbal de Morales, Dido y Eneas de Antonio Folch y Cardona y la obra anónima titulada Estragos de odio y amor. Eneas y Dido (1733) (Lida de Malkiel 1971, Garelli 1995). Posteriores a la traducción de Arellano son Dido abandonada de Francisco Durán (1792) y Dido abandonada (1792) de Alfonso de Solís y Wiñacourt (Garelli 1993).

23 Sobre Apostolo Zeno véase pág. 350-351.
} 
que todos creen muerto), que se hace pasar por ilirio y quiere matar a Pirro, sin embargo, le salva la vida cuando intentan matarlo. Volumnio y Sestia escapan, pero Fabricio hace regresar a su hija y tiene que juzgar a Volumnio por orden de Pirro. Finalmente éste, conmovido por la honestidad de padre e hija, da la paz a Roma sin pedir nada a cambio y deja libres a Sestia y Volumnio. Las fuentes clásicas sobre este personaje son Valerio Máximo, Floro, Cicerón (De officiis), Justino, Aulo Gelio, Eutropio y Plutarco (Pirro), autores que seguramente Zeno conocía.

Entre las obras de Arellano recoge Fernández González (2003, p.731) una titulada Fabio Máximo (1797), pero no da noticia de su paradero y no aparece en ninguno de los catálogos de bibliotecas consultados. Quizá sea una versión de Lucio Papirio dittatore (1719) de Apostolo Zeno, ya había traducida por Ramón de la Cruz en 1775 con el título El severo dictador y el vencedor delincuente, Lucio Papirio y Quinto Fabio.

Marco Antonio y Cleopatra $(1793,1801,1816,1821)$ es una obra aparentemente original, inspirada quizá en algunas de las siguientes fuentes clásicas: la Vida de Marco Antonio de Plutarco, Horacio, Lucano, Flavio Josefo, la Eneida de Virgilio, Apiano, Plinio el Viejo, Suetonio (El divino Julio César) y Dion Casio. También debió de recibir influencia de las obras españolas que tratan el tema ${ }^{24}$, de Anthony and Cleopatra (1607) de Shakespeare, etc. Cleopatra y Marco Antonio están en Alejandría enamoradísimos el uno del otro. Octaviano quema las naves de Antonio y Alejandría por sus terribles celos. Cleopatra acude a Octaviano y, cuando oye que éste ha tomado la ciudad y ha apresado a Antonio, decide ofrecerse en lugar de su amado, pero el futuro emperador no está dispuesto a dejar sin castigo a su rival. Éste escapa y, al oír que la reina ha muerto, entre sus desconsoladas palabras pronuncia dos versos, «Ay dulces prendas por mi mal halladas / dulces y alegres cuando en otro tiempo», que evocan los dos primeros / «¡Oh dulces prendas por mí mal halladas, / dulces y alegres cuando Dios quería!» de un soneto de Garcilaso de la Vega, antes de darse muerte. Entonces llega Cleopatra, ve sin vida a su amado y se quita la vida con áspides, emulando a Tisbe y a Julieta, tras maldecir a Octaviano, que manda recoger los cuerpos y promete eternizar su fama para que sirvan de escarmiento a futuros ciegos amantes.

La Atenea $(1792,1813)$ es una traducción libre en verso de la Atenaide, ovvero Gli affetti generosi (1762) de Metastasio, una de las dos obras romanas de Metastasio, junto con Giustino, que Céspedes no tradujo. Aunque el emperador Teodosio II está profundamente enamorado de la griega Atenea en secreto, está dispuesto a darla en matrimonio a su general, Marciano. También Asterio, un príncipe enamorado de Atenea, quiere su mano. Atenea ama a Teodosio y sufre ante la idea de la boda, por ello confiesa lo que le ocurre a Marciano. Éste explica a Pulqueria, la hermana de Teodosio y regente del imperio griego, que no se casará. Teodosio queda muy agradecido porque tomará por esposa a Atenea y entrega a Marciano la mano de Pulqueria, que estaba enamorada en secreto de él, quedando todos contentos. Lo que sabe-

\footnotetext{
24 Por ejemplo, Marco Antonio y Cleopatra de Diego López de Castro (f.1582), Historia de Marco Antonio y Cleopatra, última reina de Egipto $(1639,1736)$ de Alonso de Castillo Solórzano, Marco Antonio y Cleopatra de Calderón de la Barca y la obra anónima Soliloquio para la Señora Cleopatra vencida (ca. 1791-1804) dentro del volumen manuscrito Soliloquios serios y burlescos y otras piezas dramáticas inéditas.
} 
mos sobre Teodosio II nos lo transmiten Sócrates de Constantinopla en su Historia Ecclesiastica y Hermias Sozomeno en el libro IX de su Historia Ecclesiastica, ambos contemporáneos de Teodosio II. Epifanio Escolástico, ayudante de Casiodoro, tradujo ambas obras y la de Teodoreto al latín bajo el nombre de Historia tripartita, obra muy editada durante el siglo XVI. Es muy lógico que Metastasio, gran defensor del cumplimiento de las leyes, eligiese como protagonista de una de sus obras a este emperador bizantino, hijo del emperador Arcadio, que en 429 ordenó la compilación legislativa de derecho romano llamada Código Teodosiano y estaba muy entregado a las artes y las letras. Ahora bien, el tema, como en tantas obras del italiano, es el triunfo del amor, a pesar de los obstáculos. Una prueba de cómo influyen estas obras en la evolución del teatro español en general es que este argumento podría haber inspirado la comedia sentimental El precipitado (estrenada en 1773 y publicada en 1785) de Cándido María Trigueros, gran admirador de la obra del italiano y traductor de obras suyas como Endimione.

\section{CONCLUSIONES}

Cada vez se conoce mejor el teatro de la transición de la Ilustración al Liberalismo y se reconoce más la contribución de las traducciones y adaptaciones a la renovación del teatro español del siglo XVIII, pero apenas se ha estudiado la importancia de Apostolo Zeno y Pietro Metastasio, autores de profunda formación clásica, como intermediarios entre los clásicos y los autores españoles del siglo XVIII y el interés por Roma de los dramaturgos considerados «populares».

Ramón de la Cruz y Vicente Rodríguez de Arellano, como otros hombres de teatro de éxito, traducen algunas obras romanas inspiradas en autores de diversas épocas, porque encuentran a lo largo de toda la Historia de Roma personajes modélicos por sus virtudes (Eneas, Dido, Cayo Fabricio, Atilio Régulo, Lucio Papirio, Aecio, Teodosio II, Atenea) y, sobre todo, historias de amor (Dido y Eneas, Marco Antonio y Cleopatra, Teodosio II y Atenea, Aecio y Fulvia, Quinto Fabio y Emilia) y con ellas logran éxito, como prueban las múltiples reediciones de sus obras. Por otro lado, algunos como Rodríguez de Arellano componen obras aparentemente originales (La noche de Troya, Marco Antonio y Cleopatra), inspirándose quizá en los clásicos grecolatinos, pero también en autores españoles, en Shakespeare, etc.

Es destacable que Ramón de la Cruz elija traducir tres obras sobre episodios de la República protagonizados respectivamente por Cayo Fabricio, Lucio Papirio y Atilio Régulo, así como otra sobre el final del Imperio protagonizada por Aecio. Los cuatro varones romanos que dan título a las obras se caracterizan por ser ciudadanos ejemplares a los que no les importan las consecuencias derivadas de mantenerse fieles a su palabra a toda costa. Por otro lado, resulta llamativo que Ramón de la Cruz imponga nuevos títulos a sus versiones que son más extensos que los originales y hablan un poco más del protagonista o dan algún detalle del argumento, a diferencia, por ejemplo, de Rodríguez de Arellano, que respeta el título original en sus traducciones de Metastasio. Además compuso una Introducción para la tragedia Numancia destrui- 
da de Ignacio López de Ayala (1778), porque conoce y defiende la tragedia neoclásica española de tema nacional.

Rodríguez de Arellano, a pesar de que Alberto Lista lo incluyó en la que llamó despectivamente «escuela de Comella» y la crítica neoclásica lo trató mal, no sólo conoce la obra de Metastasio y Zeno y adapta Dido abandonada y Atenea del primero y Cayo Fabricio del segundo, sino que él mismo conoce a los clásicos y a los autores modernos que abordan sus temas y lo plasma en obras originales de temática romana, $L a$ noche de Troya y Marco Antonio y Cleopatra. Lo cual es muy meritorio, porque le suponía mucho más esfuerzo y tiempo y la misma ganancia que las traducciones.

También es llamativo que los personajes que interesan a estos autores coinciden sólo en parte con los que interesaron a los autores precedentes que habían cultivado el género (Tarquinio y Lucrecia, Coriolano, Julio César, Marco Antonio y Cleopatra, Nerón, Viriato, etc.) y a los autores que continuaron cultivando el género en el siglo XIX (Catilina, los hermanos Graco, Lucrecia, Virginia, Lucio Junio Bruto -el fundador de la República-, Marco Junio Bruto -el asesino que quitó de César-, los emperadores Nerón, Tiberio, Calígula, etc.). Sin duda, esto se debe a que en cada época los hombres de teatro quieren transmitir diferentes valores e ideas políticas al gran público y eligen entre un vasto elenco a los personajes y las historias que pueden encarnarlos mejor.

\section{REFERENCIAS BIBLIOGRÁFICAS}

Abalada, V.E.T.M. (2011), Metastasio por Francisco Luiz Amerno. Ópera, poder e literatura nas reformas do Portugal setecentista, Tesis, Brasil, Universidade Federal do Estado do Rio de Janeiro, UNIRIO.

Aguilar PIÑAL, F. (1981), Bibliografía de autores españoles del siglo XVIII, 7, Madrid, CSIC.

Angulo Egea, M. (2004), El teatro popular del siglo XVIII, Liceus, E-Excellence, $<\mathrm{http}: / / \mathrm{www}$. liceus.com/bonos/compra1.asp?idproducto $=234 \mathrm{X}>$.

ArCE, J. (1968), «El conocimiento de la literatura italiana en la España de la segunda mitad del siglo XVIII», en ARCE, J. - Glendinning, N. - Dupuis, L. (eds.), La literatura española del siglo XVIII y sus fuentes extranjeras, Oviedo, Cátedra Feijoo, pp.7-45.

Bittoun-Debruyne, N. (1995), «Traduction, adaptation et distorsion: Ramón de la Cruz et Marivaux», en LAfarga, F. - RibAs, A. - TricÁs, M. (eds.), La traducción. Metodología; Historia; Literatura: ámbito hispanofrancés, Barcelona, P.P.U, pp.247-254.

CARreras, J.J. - LeZA, J.M. (2000), «La recepción española de Metastasio durante el reinado de Felipe X (ca. 1730-1746)», en Sommer-Mathis, A.- Hilscher, E. (eds.), Pietro Metastasio (1698-1792), uomo universale, Viena, Österrischen Akademie des Wissenshaften, pp. 250267.

Cotarelo y Mori, E. (1899), Don Ramón de la Cruz y sus obras: ensayo biográfico y bibliográfico, Madrid, Imp. José Perales y Martínez.

FERnÁNDEZ CABEZÓn, R. (1989), «Influencia de Metastasio en la comedia heroica de Gaspar de Zavala y Zamora», Anuario de Estudios filológicos 12, 81-87.

Fernández Fernández, O. (2001), «La Clemencia de Tito de Metastasio en la traducción de Luzán y la visión de la ópera a través de los neoclásicos españoles del siglo XVIII», Dieciocho: Hispanic Enlightenment 24, 217-244. 
FERNÁNDEZ GONZÁLEZ, Á.R. (2003), «Dos dramaturgos navarros en la transición del siglo XVIII al XIX», Príncipe de Viana 230, 715-736.

Garelli, P. (1993), «El mito de Dido a finales del siglo XVIII: Dido abandonada de A. de Solís y Wiñacourt, duque de Montellano», en CALDERA, E. - Froldi, R. (eds.), EntreSiglos 2, Roma, Bulzoni, pp.155-161.

Garelli, P. (1995), «Dos adaptaciones de Dione abbandonata de Pietro Metastasio en el teatro español de la segunda mitad del siglo XVIII» en Lafarga, F. - Dengler, R. (coords.), Teatro y Traducción, Barcelona, Universitat Pompeu Fabra, pp.95-107.

GARELli, P. (1997), «Metastasio y el melodrama italiano», en LAFARGA, F. (coord.), El teatro europeo en la España del siglo XVIII, Lleida, Universitat de Lleida, pp.127-138.

GuILLÉn, C. (1985), Entre lo uno y lo diverso. Introducción a la literatura comparada, Barcelona, Crítica.

Lapeña Marchena, O. (2004), «La imagen del mundo antiguo en la ópera y en el cine. Continuidad y divergencia», Veleia 21, 201-215.

Lida De MALKIEL, Ma .R. (1971), Dido en la literatura española. Su retrato y defensa, Londres, Tamesis Books.

MARCo García, A. (1998), «Traducciones de teatro italiano en la colección "Teatro selecto, antiguo y moderno, nacional y extranjero (1866-1869)"’, en DíAz LARIOS, L.F. - MirALLES, E. (coords.), Del romanticismo al realismo: actas del I Coloquio de la Sociedad de Literatura Española del Siglo XIX, Barcelona, Publicacions Universitat de Barcelona, pp.213-220.

MARTín de Doria, C. (2002), «¡Estreno! ¡Estreno! ¡Estreno! ¡Ahora la Pasión de Dido y Eneas en la Ópera!», Espéculo. Revista de estudios literarios, http://www.ucm.es/info/especulo/ numero21/opera.html.

Martín Puente, C. (2003), «La figura de César en las tragedias españolas del siglo XIX», CFC(L) 23, 227-249.

MARTín Puente, C. (2005a), «El drama y la novela históricos de tema romano en el siglo XIX», en GARCÍA JuRADO, F. (comp.), Historiografía de la literatura grecolatina en el siglo XIX español: espacio social y literario, An. LI de Analecta Malacitana, Málaga, Universidad de Málaga, pp. 317-338.

MARTín Puente, C. (2005b), «Nerón como personaje de tres tragedias españolas del siglo XIX», $C F C(L) 25,157-174$.

Martín Puente, C. (2005c), «Breve estudio sobre Tiberio (1863), una tragedia de Benito Vicens y Gil de Tejada», en CosTAS, J. (coord.), Ad amicam amicissime scripta, 2, Madrid, UNED, pp.149-157.

Martín Puente, C. (2009a), «Dos tragediógrafos del XIX fascinados por la historia de Roma: José María Díaz y Benito Vicens y Gil de Tejada», en Maestre Maestre, J.Ma Pascual Barea, J. - Charlo Brea, L. (eds.), Humanismo y pervivencia del mundo clásico, 5, Alcañiz - Madrid, IEH-CSIC, pp.2397-2411.

Martín Puente, C. (2009b), «Lucrecia y Virginia, dos heroínas romanas en el teatro español del siglo XIX», en LóPeZ CRIADO, F., Héroes, Mitos y Monstruos en la Literatura Española Contemporánea, Santiago de Compostela, Andavira, pp. 19-25.

Martín Puente, C. (2010), «La historia de Lucrecia en prosa y en verso», en LuQue, J. Rincón, Ma.D. - VelázQuez, I. (eds.), Dulces camenae. Poética y poesía latinas, Jaén Granada, Editorial Universidad de Granada, pp.1359-1370.

Molina Castillo, F. (1999), «Esteban de Arteaga, crítico de Metastasio», Dieciocho: Hispanic Enlightenment 22, 61-75. 
Rossi, G.C. (1967), «Metastasio, Goldoni, Alfieri y los jesuitas españoles en Italia», en Rossi, G.C. (ed.), Estudios sobre las letras en el siglo XVIII, Madrid, Gredos, pp.248-301.

SAla VAlldaura, J.Ma . (1994), «Los jesuitas expulsos y la tragedia entre España e Italia», Bulletin Hispanique 96,153-166.

Stoudemire, S.A. (1941), «Metastasio in Spain», Hispanic Review 9, 184-191.

TATTI, M. (2001), «La romanità rivisitata dei melodrammi di Metastasio», en SAla Di Felice, E. - CAira LumetTI, R.M. (eds.), Il melodramma di Pietro Metastasio: la poesia, la musica, la messa in scena e l'opera italiana del Settecento: Atti del Convegno Internazionale di Studi, Roma, 2-5 dicembre 1998, Roma, Aracne, pp.267-303.

VidAl, J.L. - CABRERA, R. (2005), «Notas (incluso musicales) a la tradición de la Historia Augusta en el siglo XVIII», en Bonamente, G. - MAYER, M. (eds.), Historiae Augustae IX: Colloquium Barcenonense. Atti dei convegni sulla Historia Augusta, Bari, Edipuglia, pp.307- 318. 